\title{
Methodology Report \\ Effective and Steady Differentiation of a Clonal Derivative of P19CL6 Embryonal Carcinoma Cell Line into Beating Cardiomyocytes
}

\author{
Itsuki Mueller, Ryosuke Kobayashi, Takayuki Nakajima, Maki Ishii, and Kazushige Ogawa \\ Department of Veterinary Anatomy, Graduate School of Life and Environmental Sciences, Osaka Prefecture University, \\ 1-58 Rinku-Ohraikita, Izumisano, Osaka 598-8531, Japan \\ Correspondence should be addressed to Kazushige Ogawa, kogawa@vet.osakafu-u.ac.jp
}

Received 11 August 2009; Revised 1 December 2009; Accepted 25 December 2009

Academic Editor: Leon Spicer

Copyright (c) 2010 Itsuki Mueller et al. This is an open access article distributed under the Creative Commons Attribution License, which permits unrestricted use, distribution, and reproduction in any medium, provided the original work is properly cited.

The P19CL6 cell line is a useful model to study cardiac differentiation in vitro. However, large variations were noticed in the differentiation rates among previous reports as well as our individual experiments. To overcome the unstable differentiation, we established P19CL6-A1, a new clonal derivative of P19CL6 that could differentiate into cardiomyocytes more efficiently and stably than the parent using the double stimulation with 5-Aza and DMSO based on the previous report. We also introduced a new software, Visorhythm, that can analyze the temporal variations in the beating rhythms and can chart correlograms displaying the oscillated rhythms. Using P19CL6-A1-derived cardiomyocytes and the software, we demonstrated that the correlograms could clearly display the enhancement of beating rates by cardiotonic reagents. These indicate that a combination of P19CL6-A1 and Visorhythm is a useful tool that can provide invaluable assistance in inotropic drug discovery, drug screening, and toxicity testing.

\section{Introduction}

Heart disease, including coronary heart disease, cardiomyopathy, and heart failure, causes functional deterioration and/or failure as well as myocardial cell death. It is one of the leading causes of death in advanced countries because adult cardiomyocytes are highly differentiated and have a limited regenerative capacity; therefore, significant loss of myocardium is mostly irreversible. Cell regeneration therapy is a promising new approach for myocardial repair, $[1,2]$ and in this context, there has been considerable basic research on the mechanisms of cell development into cardiomyocytes using somatic and embryonic stem (ES) cells as well as embryonic carcinoma cells [3-6]. P19 embryonic carcinoma cells are one of the first among such cells to demonstrate differentiation into cardiomyocytes [7] and have contributed extensively to the elucidation of the development mechanisms from stem cells into cardiomyocytes $[4,5,8]$. P19 cells are derived from a teratocarcinoma in $\mathrm{CH} 3 / \mathrm{He}$ mice and can differentiate into all 3 germ layers [9]. Culture and differentiation of the cells is simple, and this advantage has enabled their extensive application for decades. They continuously grow in serum-supplemented media, can retain an undifferentiated cell state without a feeder cell layer unlike ES cells, and their differentiation can be controlled by nontoxic reagents. Primarily, cell aggregate formation in suspension culture under $0.5-1.0 \%$ dimethyl sulfoxide (DMSO) followed by the reagent application in adhesion culture has been used to induce cardiomyocyte differentiation of P19 cells $[7,8,10]$. We examined the differentiation of P19 cells into cardiomyocytes by the above general method; however, it resulted in large variations in the differentiation rate and low differentiation efficiencies among individual experiments, even though high differentiation efficiencies have been reported previously $[7,8,10]$.

P19CL6 cells, clonal derivatives of P19 cells, were established by Habara-Ohkubo [11]. These subline cells can be differentiated into spontaneously beating cardiomyocytes by treatment with $1 \%$ DMSO in adhesion culture over a period of 10 days or weeks without cell aggregate formation in suspension culture and more efficiently as compared to the parent cells. Therefore, P19CL6 cells may be more useful to 
examine the differentiation mechanisms of cardiomyocytes in vitro. Recently, Ohtsu et al. [12] introduced a double stimulation method for cardiomyocyte differentiation from P19CL6 cells. They demonstrated that cells exposed to $10 \mu \mathrm{M}$ 5-azacytidine (5-Aza) for 24 hours prior to treatment with $1 \%$ DMSO differentiated into cardiomyocytes more effectively than the widely used single stimulation method described above. In order to produce a large number of cardiomyocytes, we induced differentiation of P19CL6 cells into cardiomyocytes by the double stimulation method to examine the differentiation efficiency; however, it resulted in large variations in the differentiation rates among individual experiments, as in the case of P19 cells. However, notably, the double stimulation method elicited differentiation from P19CL6 cells most efficiently among the several differentiation methods as long as it was in vitro in our laboratory. We also noticed large variations in the differentiation rates among previous reports on P19CL6 [12-14] as well as P19 cells $[8,10,15,16]$ and this may imply a fundamental problem of the cells in themselves and/or the differentiation methods. To overcome this difficulty, we attempted to establish a subline from P19CL6 cells, and accordingly, we could introduce a new subline of cells, that is, P19CL6-A1 cells, that could efficiently and stably differentiate into cardiomyocytes by a differentiation method based on the double stimulation method with many modifications. In the present study, we also introduce a software program, VisoRhythm, which can analyze the temporal variations in the beating rhythms on moving images and chart correlograms displaying the oscillated rhythms on a Windows computer. Because the spontaneously beating cardiomyocytes differentiated from P19CL6-A1 cells form large cell clusters, their contractions are large and strong. This feature may prove to be quite suitable for oscillated rhythm analysis based on moving images, and accordingly, we used this software to successfully display the increase in the cardiomyocyte beating rates on correlograms and dose-response curves on treatment with serially diluted cardiotonic reagents. This may indicate that P19CL6-A1 cells and the above software are useful tools for pharmacological screening tests.

\section{Materials and Methods}

2.1. Animals. Balb/c mice of either sex maintained under standard housing and feeding conditions were used. The ventricles of the hearts dissected from mice aged 8 weeks and 16.5 days post coitum ( $\mathrm{dpc}$ ) fetuses were examined by reverse transcription PCR (RT-PCR). The animal experimentation protocols were approved by the University's Animal Research Committee.

2.2. Cell Culture and Cloning. P19CL6 cells were obtained from RIKEN BioResource Center (Ibaraki, Japan). The cells were cultured in a tissue culture-grade dish and grown in alpha-modified Eagle's minimal essential medium ( $\alpha$-MEM; Sigma-Aldrich Japan K.K., Tokyo) supplemented with Lglutamine (4 mM; Gibco BRL, Carlsbad, CA) or Dulbecco's modified Eagle's minimal essential medium (DMEM; SigmaAldrich Japan K.K.) containing 5-10\% heat-inactivated fetal bovine serum (FBS; JRH Biosciences, Lenexa, KA) and penicillin and streptomycin $(100 \mathrm{U} / \mathrm{mL}$ and $100 \mu \mathrm{g} / \mathrm{mL}$, resp.; Sigma-Aldrich Japan K.K.). They were maintained in a 5\% $\mathrm{CO}_{2}$ atmosphere at $37^{\circ} \mathrm{C}$.

Several subclones were isolated from the P19CL6 cells by the common cloning ring technique. Each clonal colony was expanded increasingly into larger wells and dishes and frozen until use. Two types of cell colonies were derived from a single cell: one, growing horizontally to form a single cell layer on a dish and the other, growing both horizontally and vertically to form cell aggregates of multicell layers like embryoid bodies or cell aggregates in suspension culture prepared using bacterial-grade dishes $[5,8,13]$. Both cell types were collected for the cardiac differentiation experiment; however, the latter were considerably more efficient in differentiating into cardiomyocytes.

Among the several differentiation methods, the one proposed by Ohtsu et al. [12] elicited most efficient cardiomyocyte differentiation from parent P19CL6 cells as long as the experiment was in vitro in our laboratory; however, it also led to a fundamental difficulty, that is, high variations in the differentiation efficiencies among individual experiments. Hence, we modified the above method in order to adapt it to our subclonal cells as well as to the parent cells. The differentiation conditions that we primarily considered were the concentration and/or exposure duration of the differentiation reagents, the concentration of FBS in the culture medium ( $\alpha$-MEM or DMEM), and coating reagents. They were as follows: 5-azacytidine (5-Aza; Sigma-Aldrich Japan K.K.): concentration: 5, 10, 15, 20, 30, and $40 \mu \mathrm{M}$ and exposure duration: 24,48 , and 72 hours; dimethyl sulfoxide (DMSO, Sigma-Aldrich Japan K.K.): concentration: 0.5, 1.0, 1.5, and 2.0\%; FBS in the differentiation medium: concentration: $2.5,5.5,6.5,7.5$, and $10 \%$; and the use of a culture dish coated with or without collagen $\left(3.0 \mu \mathrm{g} / \mathrm{cm}^{2}\right.$, Type I-A; Nitta Gelatin Inc., Osaka) or Matrigel $\left(3.0 \mu \mathrm{g} / \mathrm{cm}^{2}\right.$; BD Biosciences, San Jose, CA). Accordingly, we found a subclone, designated A1, which is the most efficiently differentiated into cardiomyocytes under the differentiation conditions below and used it for further experiments to evaluate the differentiation efficiency. We also found the optimum conditions that could be applied to the parent P19CL6 cell line, and the use of these conditions yielded almost the same results as those yielded by the method of Ohtsu et al. [12]; the description has been provided below.

2.3. Differentiation. The differentiation efficiencies of the subline, P19CL6-A1, and the parent cell line, P19CL6, were compared. The differentiation conditions were summarized in Table 1.

The cells were plated at a density of $5.0 \times 10^{5}$ cells/well on 6-well plates or on a $35-\mathrm{mm}$ tissue culture-grade dish coated with collagen $\left(3.0 \mu \mathrm{g} / \mathrm{cm}^{2}\right)$ and containing the growth medium ( $\alpha$-MEM with 6.5\% FBS for P19CL6 cells or DMEM with 7.5\% FBS for P19CL6-A1 cells) and were incubated in a $5 \% \mathrm{CO}_{2}$ atmosphere at $37^{\circ} \mathrm{C}$. The next day, when cells reached $\sim 95 \%$ confluence, the medium was replaced with a growth medium containing $10 \mu \mathrm{M} \mathrm{5-Aza} \mathrm{in} \mathrm{order}$ to induce differentiation. The P19CL6 and P19CL6-A1 cells 
TABLE 1: The conditions of differentiation protocol and differentiation efficiency for P19CL6 and P19CL6-A1 cells.

\begin{tabular}{|c|c|c|c|}
\hline Cell line & P19CL6 & PI9CL6-Al & P19CL6 \\
\hline Differentiation protocol & Basal protocol & Developed protocol & Ohtsu et al. [12] \\
\hline Medium & $\alpha$-MEM & DMEM & $\alpha$-MEM \\
\hline FBS: concentration & $6.5 \%$ & $7.5 \%$ & $10 \%$ \\
\hline \multirow{2}{*}{ 5-Aza: concentration and incubation time } & $10 \mu \mathrm{M}$ & $10 \mu \mathrm{M}$ & $10 \mu \mathrm{M}$ \\
\hline & 24 hours & 72 hours & 24 hours \\
\hline \multirow{2}{*}{ DMSO: concentration and incubation time } & $1 \%$ & $1 \%$ & $1 \%$ \\
\hline & $\geq 16$ days & $\geq 14$ days & $\sim 16$ days \\
\hline Coating & $\begin{array}{l}\text { Collagen } \\
\text { (Type I-A) }\end{array}$ & $\begin{array}{c}\text { Collagen } \\
\text { (Type I-A) }\end{array}$ & - \\
\hline$\alpha$-actin-positive cell area to total field ${ }^{*}$ & $7.0 \%$ & $38.3 \%$ & - \\
\hline Relative intensity of $\alpha$-MHC mRNA expression** & 1.0 & 1.77 & 一 \\
\hline
\end{tabular}

*,** Differentiation efficiency measured by immunofluorescence microscopy $(*)$ and RT-PCR $(* *)$ on day 16.

were treated with 5-Aza for 24 and 72 hours, respectively, and the 5-Aza-containing medium was changed every 24 hours. After treatment with 5-Aza, the cells were incubated in the growth medium containing 1.0\% DMSO for more than 16 days. The DMSO-containing medium was also changed everyday in order to remove the cell debris resulting from cell death. The experimental days were numbered consecutively beginning from the day after the first day of treatment with 5-Aza (day 0).

2.4. Immunofluorescence Microscopy. P19CL6 and P19CL6A1 cells were cultured on glass coverslips coated with collagen $\left(3.0 \mu \mathrm{g} / \mathrm{cm}^{2}\right)$. Cells on day 16 were washed twice with Hanks' balanced salt solution (HBSS; Sigma-Aldrich Japan K.K.) and then fixed with $4 \%$ paraformaldehyde in PBS for 30 minutes at $4^{\circ} \mathrm{C}$. After the fixation, cells were rinsed twice in cold PBS, treated with $0.1 \%$ Triton X-100 in PBS for 20 minutes at room temperature and again rinsed twice in PBS. In order to reduce autofluorescence, cells were treated with $50 \mathrm{mM} \mathrm{NH}_{4} \mathrm{Cl}$ in PBS for 10 minutes at room temperature. Then cells were blocked in a humid chamber with PBS containing 3\% normal goat serum (NGS; SigmaAldrich Japan K.K.) for 30 minutes and then incubated with the anticardiac $\alpha$-actin antibody (Sigma-Aldrich Japan K.K.; $10 \mu \mathrm{g} / \mathrm{mL}$ in PBS containing 3\% NGS) for 16 hours at $4^{\circ} \mathrm{C}$. After washing with PBS, cells were incubated with Alexa488-conjugated goat antimouse IgG (Molecular probes, Inc., Eugene, OR) for 30 minutes at room temperature, rinsed in PBS and mounted with Permafluor (Thermo Fisher Scientific Inc., Fremont, CA). Cells were photographed with fluorescence microscopes (IX71, Olympus Co., Tokyo). The specificity of the immunofluorescence staining was verified by incubations without the primary or secondary antibodies and no specific fluorescence was observed in the control. For quantitative analysis of rates of differentiation into cardiomyocytes, we measured ratios of cardiac $\alpha$-actin-positive cell areas to total areas of microscopic fields using Image J software (ver. 1.41; National Institutes of Health, Bethesda, $\mathrm{MD})$. For this purpose 10 random fields per coverslip were photographed. Autofluorescence from multilayer cell regions was rather strong but $\alpha$-actin-specific fluorescence was easily discriminated from the autofluorescence because $\alpha$-actinpositive cells emerged as high-intensity cells in cell clusters (see Figure 2). In this way we counted out autofluorescence regions. Sixty fields were examined in each cell type and the results from six independent experiments were summarized as mean $\pm \mathrm{SE}$. Unpaired $t$-test was carried out to compare the differentiation efficiency between the two cell types.

2.5. Reverse Transcription PCR (RT-PCR) Analysis. Total RNA was isolated from the cultured P19CL6 and P19CL6A1 cells on days $0,3,7$, and 16 , and from the cardiac ventricles of 8 -week-old adult mice and $16.5 \mathrm{dpc}$ fetuses using the TRIZOL reagent (Invitrogen Japan K.K., Tokyo). One microgram of total RNA was transcribed into firststandard cDNA using M-MLV reverse transcriptase, RNase $\mathrm{H}^{-}$(Promega, Madison, WI), and oligo (dT) primer according to the manufacturer's instructions. For detection of GATA4 and Nkx2-5, the specific transcription factors for cardiac differentiation [17], and of the alpha myosin heavy chain $(\alpha-\mathrm{MHC})$, which is indispensable for cardiomyocyte contraction, $1 \mu \mathrm{L}$ of the reaction mix (out of the total $25 \mu \mathrm{L}$ ) as the reverse-transcribed DNA template was amplified by PCR-40 cycles for GATA4 and Nkx2-5 and 25 cycles for $\alpha$-MHC. After amplification, the PCR products were separated on $1.2 \%$ agarose gel and visualized by ethidium bromide staining. The expression levels of GATA4, Nkx25 , and $\alpha$-MHC mRNAs were compared between P19CL6 and P19CL6-A1. They were determined from 3 independent experiments and normalized by reference to the expression levels of GAPDH mRNA (23 cycles of PCR). All analyses were performed on Excel 2007. The values were expressed as the mean \pm SE that was represented by ratios to the mean values of the P19CL6 cells in the basal protocol on day 16 as 1.0 according to the differentiation protocol. Unpaired $t$-test was carried out for statistical analysis. The following primer pairs were used: GATA4, 5'-GTTGTGGTGGTGGGTTTTTC-3' (forward) and 5'TTTGATGTTCCTGGGAGAGG-3' (reverse); Nkx2-5, $5^{\prime}$ TCTCCGATCCATCCCACTTTATTG- $3^{\prime}$ (forward) and $5^{\prime}$-TTGCGTTACGCACTCACTTTAATG-3' (reverse); $\alpha$ MHC, $5^{\prime}$-TACCTCATGGGGCTGAACTC- $3^{\prime}$ (forward) and 
5'-CGAACATGTGGTGGTTGAAG-3' (reverse); GAPDH, $5^{\prime}$-GACTTCACTCACGGCAAATT- $3^{\prime}$ (forward) and $5^{\prime}$ TCCTCAGTGTAGCCCAAGAT-3' (reverse).

2.6. Contraction Rhythm Analysis Based on Moving Images. The $35-\mathrm{mm}$ dish with the differentiated cells were placed in a stage top microscope incubator (ONI-INU-F1; Tokai Hit, Shizuoka, Japan) mounted on an inverted microscope (DMIRB, Leica Microsystems Ltd., Heerbrugg, Switzerland) and incubated at $37^{\circ} \mathrm{C}$ in a $5 \% \mathrm{CO}_{2}$ atmosphere. Phasecontrast moving images of spontaneously beating cells were recorded through a CCD camera (COOLPIX4500; Nikon Co., Tokyo) and digitalized to mpeg2 video files ( 8 bits/channel; 704 pixels $\times 480$ pixels/frame; 30 frames/sec) using an encoder (MTU2400 FX; Canopus Co. Ltd., Kobe, Japan). The contraction rhythm of the spontaneously beating cells was analyzed based on the moving images using the following method based on the data analysis algorithm on the calculation of correlation coefficient as reported by Yamauchi et al. [18]. A small area of interest where brightness clearly oscillated due to the beating was selected from a moving image, and then, a reference frame was arbitrarily chosen from the moving image frames. Temporal variations in the correlation coefficient were calculated between the values of mean brightness of the reference frame and those of other frames in the selected area, and accordingly, a correlogram representing the contraction rhythm of the beating cells in the area of interest was displayed by the vertical coefficient and horizontal time axis. We developed a software program, VisoRhythm, which calculates the temporal variations in the correlation coefficient up to 6 rectangle areas (150-400 pixels/area) simultaneously on a single moving image on a Windows computer. The data can then be directly output into Excel to chart the correlograms, and the beat-to-beat intervals are represented by the intervals between the upward and downward peaks in each correlogram in the selected areas.

We examined the pharmacological reactions of spontaneously beating cardiomyocytes differentiated from the P19CL6-A1 cells to evaluate whether they are useful cellular tools for pharmacological screening tests. We used 3-isobutyl-1-methylxanthine (IBMX; Sigma-Aldrich Japan K.K.) and ouabain (Sigma-Aldrich Japan K.K.), which are well-known potent cardiotonic reagents, for this purpose. Phase-contrast moving images of spontaneously beating cells were recorded before and after addition of serial dilutions of each reagent $(10 \mathrm{nM}, 20 \mathrm{nM}, 70 \mathrm{nM}, 200 \mathrm{nM}, 700 \mathrm{nM}, 2 \mu \mathrm{M}$, $7 \mu \mathrm{M}, 20 \mu \mathrm{M}$, and $70 \mu \mathrm{M}$ ) into the medium. The beat-tobeat intervals on exposure to certain concentrations $(10 \mathrm{nM}$, $30 \mathrm{nM}, 100 \mathrm{nM}, 300 \mathrm{nM}, 1 \mu \mathrm{M}, 3 \mu \mathrm{M}, 10 \mu \mathrm{M}, 30 \mu \mathrm{M}$, and $100 \mu \mathrm{M})$ were obtained from the correlograms calculated on VisoRhythm. The median effective dose $\left(\mathrm{ED}_{50}\right)$ was obtained from the dose-response curve based on the beating rates on which the basal and maximum rates were represented by 0 and $100 \%$, respectively.

\section{Results}

3.1. Differentiation Conditions and Microscopic Observations. We selected the differentiation protocol suggested by Ohtsu et al. [12] for the P19CL6 cells because this method was the most efficient for cardiomyocyte differentiation from among the several differentiation methods as long as it was in vitro in our laboratory. The undifferentiated populations of the cells, however, considerably proliferated even in the differentiation medium containing $1 \%$ DMSO as a differentiation inducer and $10 \%$ FBS; hence, we reexamined the optimum concentration of FBS. We thus obtained a resultant concentration of approximately $6.5 \%$, and accordingly, the protocol for the cells was as revised as follows. Subconfluent P19CL6 cells in $\alpha$-MEM containing 6.5\% FBS were treated with $10 \mu \mathrm{M} 5$-Aza for 24 hours followed by treatment with $1 \%$ DMSO for more than 16 days (basal protocol). In case of the P19CL6-A1 cells, we modified the basal protocol by reexamining the conditions in each step according to the criteria of (1) rates of appearance of the beating cells per field and (2) dimensions of the beating area under a microscope. The cells showed a relatively high resistance to 5-Aza, and the optimum conditions were as follows. Subconfluent P19CL6A1 cells in DMEM containing 7.5\% FBS were treated with $10 \mu \mathrm{M} 5$-Aza for 72 hours followed by treatment with $1 \%$ DMSO for more than 14 days (developed protocol). We also examined the differentiation efficiencies in culture dishes coated with or without collagen or Matrigel and found the differentiation to be more effective on collagen coated dishes. The conditions for each protocol and for each cell type are summarized in Table 1.

We observed the differentiation processes under an inverted microscope to compare the morphological differences between the P19CL6 and P19CL6-A1 cells. Both cell types grew similarly in the beginning (days $0-5$ ) of the differentiation protocols. The P19CL6 and P19CL6-A1 cells reduced in number during treatment with 5-Aza due to the damage by the reagent and proliferated slightly everyday thereafter during treatment with DMSO. The cells started to grow vertically due to overconfluence, and multilayer cell regions appeared around day 5. On the P19CL6 cells multilayer cell regions were generally small and appeared like scattered islands in monolayer cell regions. However, on P19CL6-A1 cells, they were connected with each other to form mesh-like structures and expanded to comprise approximately $70-80 \%$ of the total area of the dishes during the procedure. This feature of the multilayer cell regions was similar to that of embryoid bodies or aggregates on culture with DMSO in the nonadhesive bacteriological-grade dishes. Beating cells first appeared among the P19CL6 cells differentiated by the basal protocol on day 10 and among the P19CL6-A1 cells differentiated by the developed protocol on day 11. The clusters of beating cells increased in number and size thereafter and peaked on day 16 in both cases. The peaks were retained at least till day 21 . The beating cell clusters from the P19CL6 cells were observed generally in the monolayer cell regions and less frequently on the boundary between the monolayer and multilayer regions (Figure 1(a)). The clusters, composed of small-sized beating cells densely arranged, were generally small in the monolayer regions (Figures $1(\mathrm{c})$ and $1(\mathrm{e})$ ). On the other hand, the beating cell clusters in the P19CL6-A1 cells appeared mostly in the multilayer and boundary regions (Figure 1(b)). They 


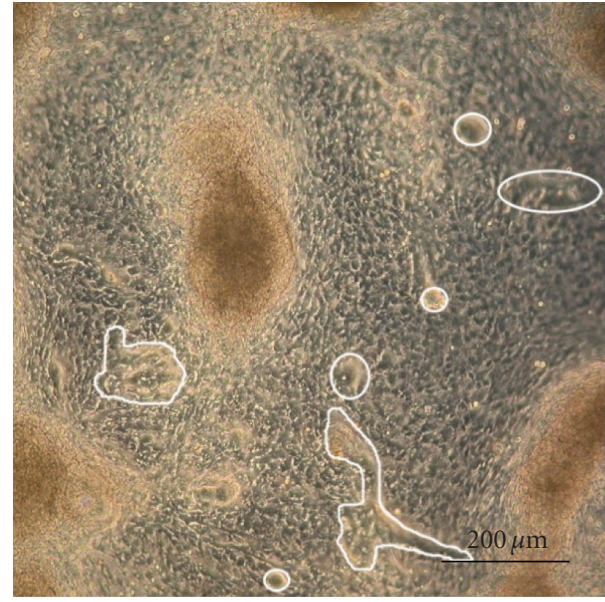

(a)

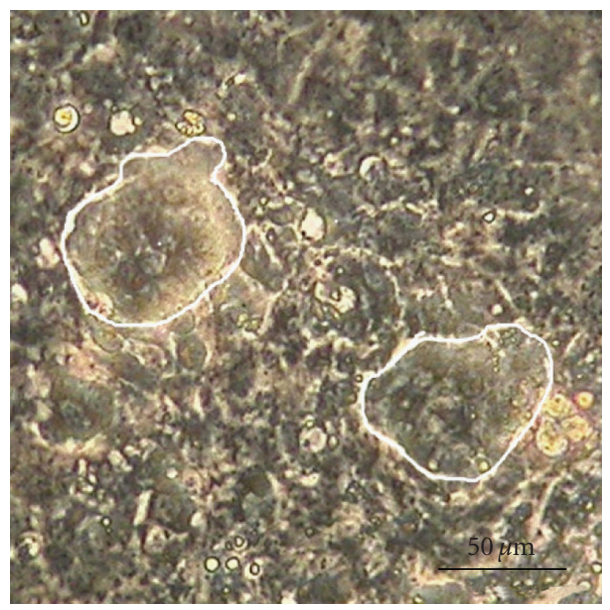

(c)

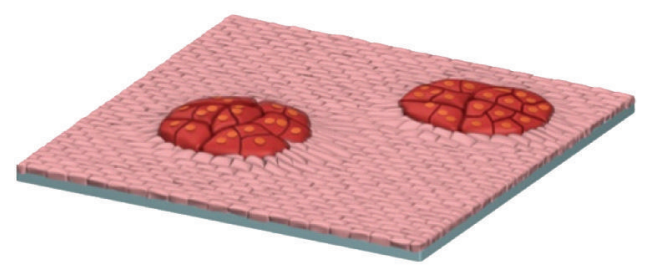

(e)

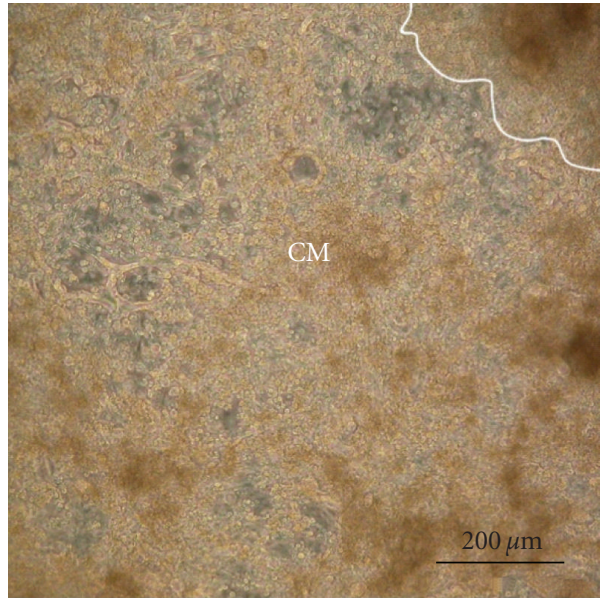

(b)

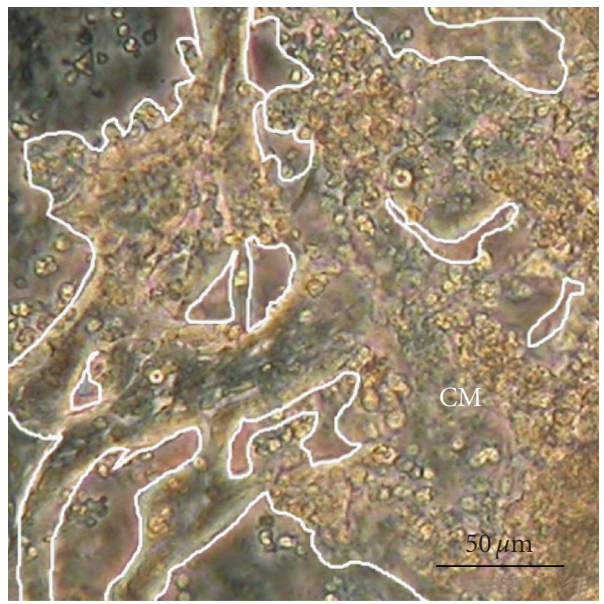

(d)

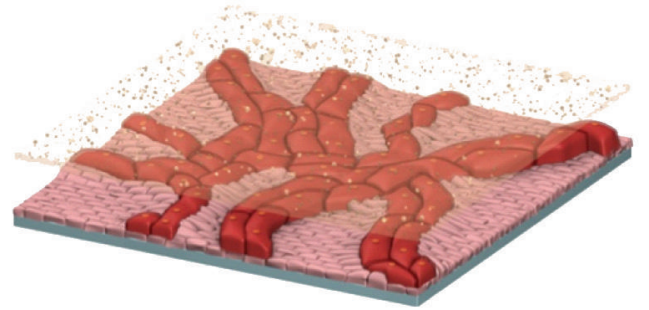

(f)

FIGURE 1: Phase-contrast micrographs in typical view of beating cardiomyocytes (CM; enclosed with a white line) differentiated from P19CL6 cells by the basal protocol ((a) and (c)), and P19CL6-A1 cells by the developed protocol ((b) and (d)) on day 16. Cardiomyocytes in (b) form the large cluster that extends beyond the visual field while those in (a) form the small clusters. The clusters of cardiomyocytes in (c) are small and round in a single cell layer region. They are composed of small-sized beating cells densely arranged. On the other hand, the cluster in (d) is large and forms a mesh-like sheet structure in multicell layers. It is composed of elongated cardiomyocytes. (e) and (f) are diagrams of (c) and (d), respectively, in which cardiomyocytes are depicted in Indian red.

were composed of elongated cells and formed mesh-like sheet structures (Figures $1(\mathrm{~d})$ and $1(\mathrm{f})$ ). They were relatively large and sometimes extended beyond the visual field under the inverted microscope through a $10 \times$ objective lens, and accordingly, the contractions were large and strong. Therefore, the beating cells differentiated from the P19CL6-
A1 cells on day 16 or later were suitable for contraction rhythm analyses based on moving images.

In order to morphologically identify cardiomyocytes differentiated from P19CL6 and P19CL6-A1 cells clearly and to compare the differentiation efficiencies between the two, we immunocytochemically examined those cells on day 16 using 


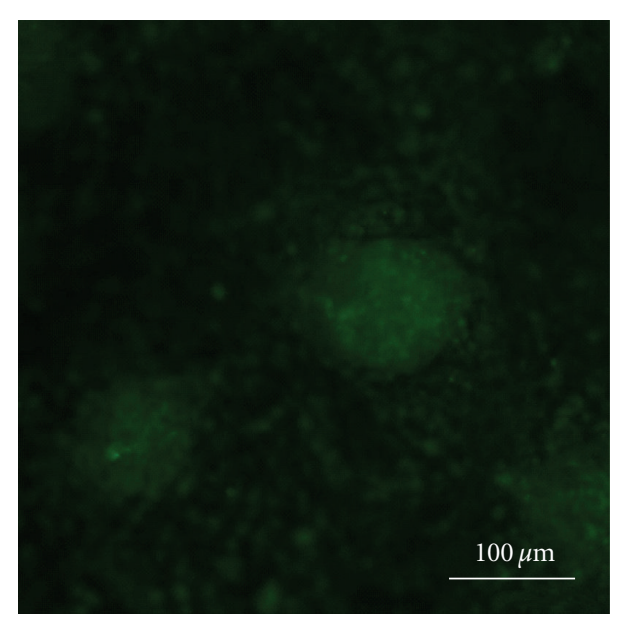

(a)

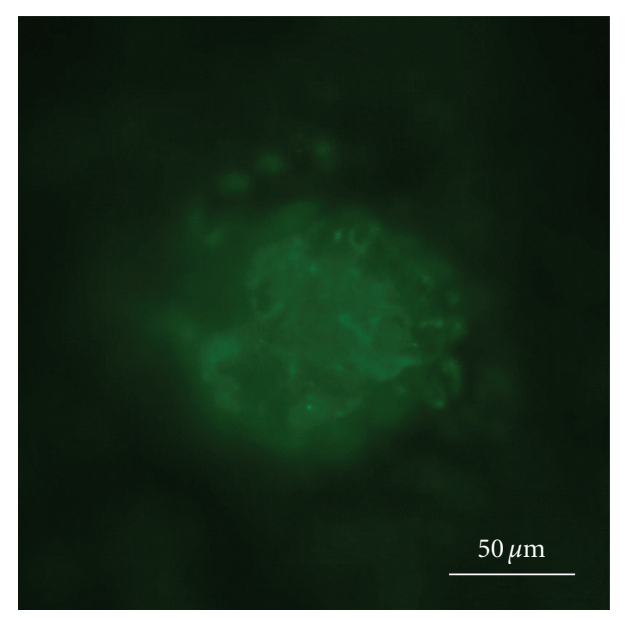

(c)

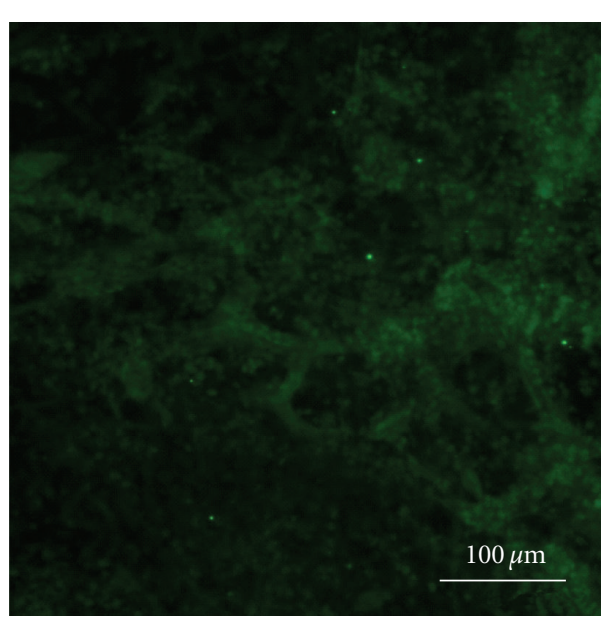

(b)

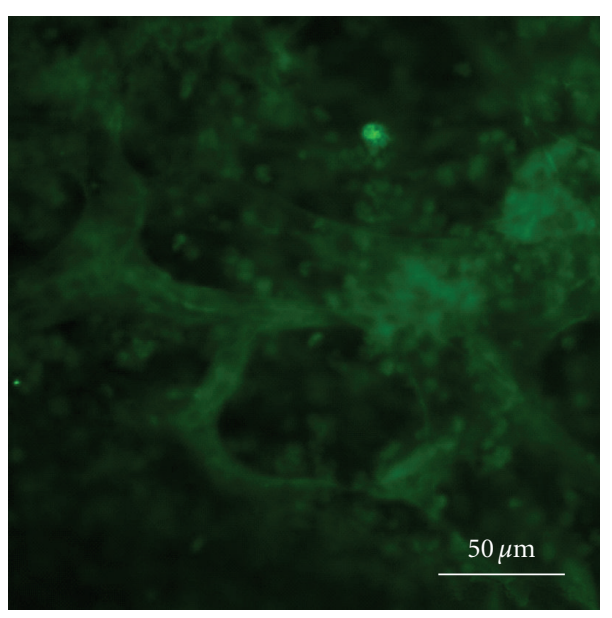

(d)

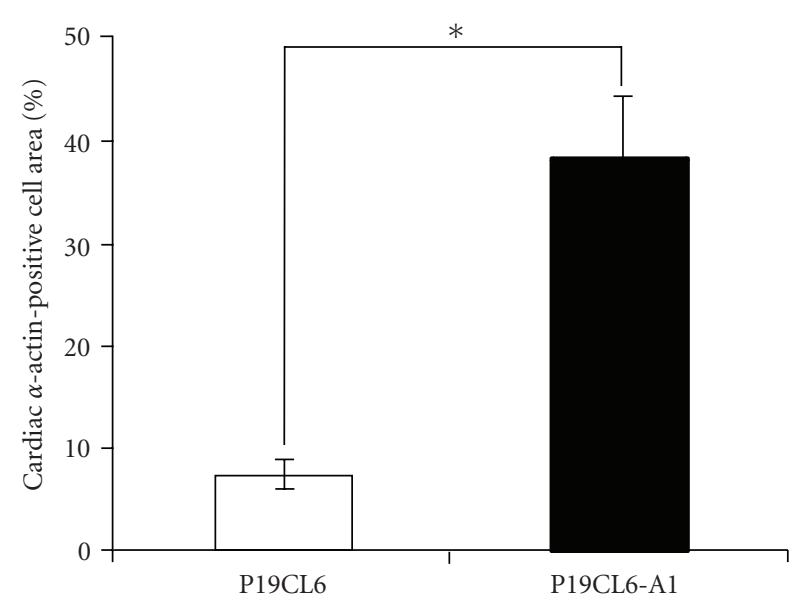

(e)

FIGURE 2: Immunofluorescence staining with anticardiac $\alpha$-actin antibody in P19CL6 cells differentiated by the basal protocol on day 16 ((a) and (c)), and P19CL6-A1 cells by the developed protocol on day 16 ((b) and (d)). ((a) and (c)) Cardiac $\alpha$-actin-positive cells, various in shape, form relatively small and round clusters. ((b) and (d)) Cardiac $\alpha$-actin-positive cells, relatively large and elongated in general, formed mesh-like sheet structures. (e) Quantitative analysis of rates of differentiation into cardiomyocytes. Ratios of $\alpha$-actin-positive cell areas to total areas of microscopic fields were calculated based on a total of 60 micrographs randomly taken from six independent experiments in each cell type and summarized as mean \pm SE. Unpaired $t$-test was carried out to compare the differentiation efficiency between the two cells. ${ }^{*} P<.01$. 
anticardiac $\alpha$-actin antibody under immunofluorescence microscopy. Cardiac $\alpha$-actin-positive cells from P19CL6 were various in shape (oval, polygonal, short spindle-shaped) and generally formed round clusters (Figures 2(a) and 2(c)). Those from P19CL6-A1 were relatively large and elongated, and formed mesh-like sheet structures (Figures 2(b) and $2(\mathrm{~d}))$. We measured ratios of cardiac $\alpha$-actin-positive cell areas to total areas of microscopic fields; the positive cell areas were $7.0 \pm 1.1 \%$ (mean \pm SE) of the total areas on P19CL6 while those were $38.3 \pm 5.7 \%$ on P19CL6-A1. The value on P19CL6-A1 was 5.5 times and significantly higher than that on P19CL6 $(P=.002$; Figure 2(e), Table 1).

3.2. Expression of Cardiac Specific mRNAs. To compare the differentiation efficiencies between the P19CL6 and P19CL6A1 cells, we examined the expression of the cardiac-specific transcription factors, GATA4 and Nkx2-5, and of the cardiacspecific myosin heavy chain, $\alpha$-MHC, by RT-PCR on the respective cells with the respective differentiation protocols listed in Table 1 on days $0,3,7$, and 16. Both GATA4 and Nkx2-5 were already expressed in both P19CL6 and P19CL6A1 cells on day 0 , that is, in the untreated cells (Figure 3(a)). The expression of the former increased from day 0 to day 16 during treatment in both groups (Figure 3(b)), while that of the latter dipped on day 3 , but increased thereafter (Figure 3(c)). On day 16, when the appearance rates of the beating cells per field and the dimensions of the beating area peaked as observed under a microscope, GATA4 expression did not differ significantly between the P19CL6 and the P19CL6-A1 cells; however, Nkx2-5 expression in the latter was significantly and 1.45 times higher than that in the former (Figure 3(c)). Alpha-MHC was not expressed till day 7 , although it was clearly expressed on day 16 in both groups (Figure 3(d)). Its expression in the P19CL6-A1 cells was significantly and 1.77 times higher than that in the P19CL6 cells (Figure 3(d), Table 1). These results indicated that P19CL6-A1 cells were more efficient than the parent in terms of cardiomyocyte differentiation. We also examined $\alpha$-MHC expression in the ventricles of 8 -week-old adult mice and $16.5 \mathrm{dpc}$ fetuses by RT-PCR to compare $\alpha$-MHC expression in the tissues with that in the P19CL6-A1 cells differentiated by the developed protocol on day 16. The expression levels were higher in the adult tissue than in the other tissue, but were almost equal between the fetal tissue and the cells on day 16 (Figure 3(e)).

3.3. Analysis of the Pharmacological Reactions of the Beating Cells Based on Moving Images. We examined the pharmacological reactions of the spontaneously beating cells differentiated from P19CL6-A1 cells by the developed protocol. For this purpose, we employed IBMX and ouabain as cardiotonic reagents, and both of them increased the beating rates. The moving images of the beating cells were recorded before and after addition of serial dilutions of each reagent. To determine the temporal variations in the beating rhythms in detail, we developed the software, Visorhythm, to analyze them based on moving images and chart correlograms displaying the oscillated rhythms. Figure 4(a) is an example of a series of correlograms corresponding to the temporal variations in the contraction rhythms of the beating cells treated with $10 \mathrm{nM}, 300 \mathrm{nM}$, and $10 \mu \mathrm{M}$; the beating rate was 1.30 times per second at the basal level and increased up to 2.30 times per second after the addition of $10 \mu \mathrm{M}$ IBMX. Figure 4(b) shows the dose-response curve to IBMX corresponding to the data in Figure $4(\mathrm{a})$, and its $\mathrm{EC}_{50}$ was $950 \mathrm{nM}$. Figures $4(\mathrm{c})$ and $4(\mathrm{~d})$ illustrate another series of correlograms and a dose-response curve to ouabain, respectively. In this case, its $\mathrm{EC}_{50}$ was $160 \mathrm{nM}$. These data indicate that the P19CL6-A1 cells and Visorhythm are useful tools for pharmacological screening tests.

\section{Discussions}

4.1. Efficient Differentiation. P19 embryonal carcinoma cells have been extensively studied for cardiac differentiation in vitro and have contributed to the elucidation of the early events in differentiation, such as the involvement of bone morphogenic proteins and their subsequent intracellular signal cascades and oxytocin and its subsequent activation of the transcription factors GATA4, Nkx2-5, and so on $[5,7,8,10,19]$. For their efficient differentiation into cardiomyocytes, prior formation of cell aggregates in suspension culture under $0.5-1.0 \%$ DMSO followed by reagent application in adhesion culture is required; however, molecular events occurring during aggregation and the necessity of their aggregation for differentiation have not yet been entirely understood [5]. High cell densities at least can trigger spontaneous differentiation from P19 cells without the formation of cell aggregates and reagent treatment $[9,10]$. On the other hand, P19CL6 cells, the clonal derivative of the P19 cells, efficiently differentiate into cardiomyocytes on DMSO treatment in adhesion culture without prior formation of cell aggregates, although high cell densities are required for effective differentiation [11]. In the present study, we introduced P19CL6-A1, a clonal derivative of P19CL6 cells, which differentiated into cardiomyocytes most efficiently among the 3 cell lines subjected to double stimulation with 5-Aza and DMSO in adhesion culture as reported by Ohtsu et al. [12], with many modifications. The P19CL6-A1 cells extensively formed multicell layers in adhesion culture under stimulation with DMSO after they reached overconfluence. They were highly packed in multicell layers like the cell aggregates of P19 cells in suspension culture. P19CL6-A1-derived cardiomyocytes, which generally formed large clusters of beating cells, almost always appeared in the multilayer regions and on the boundary regions adjacent to the monolayer regions. These findings, in addition to the above differentiation characteristics in the other 2 cell types, may indicate that cell-to-cell contact all around, that is, not only from side to side but also from top to bottom, is a key event in the differentiation of P19 cells and their derivatives. Because three-dimensional contact can be achieved by the formation of multicell layers, a clonal derivative differentiating more efficiently into cardiomyocytes than P19CL6-A1 may be established when the dimensions of the multilayer regions is employed as a criterion for clonal selection from P19CL6 cells. Further 


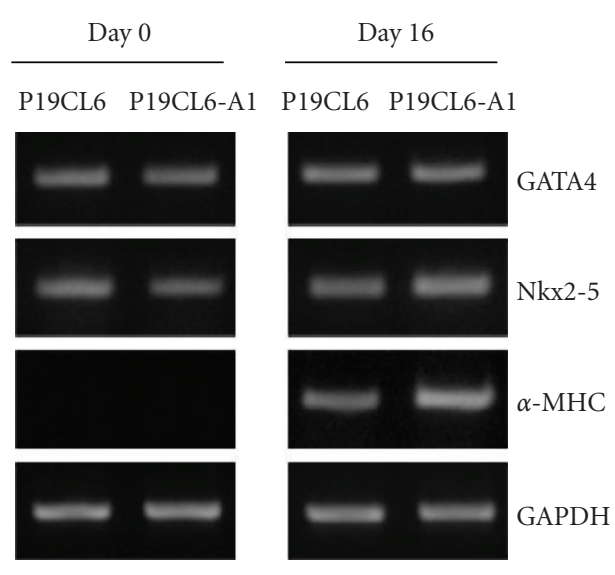

(a)

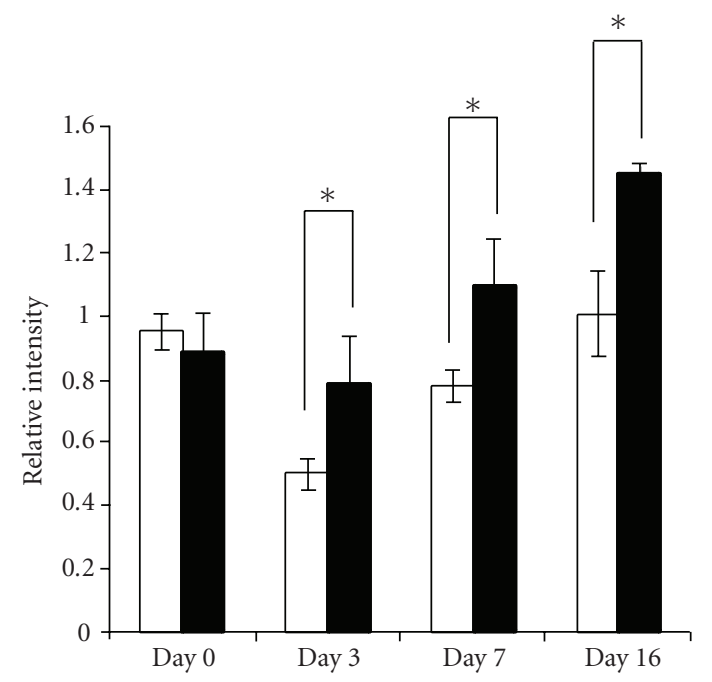

(c)

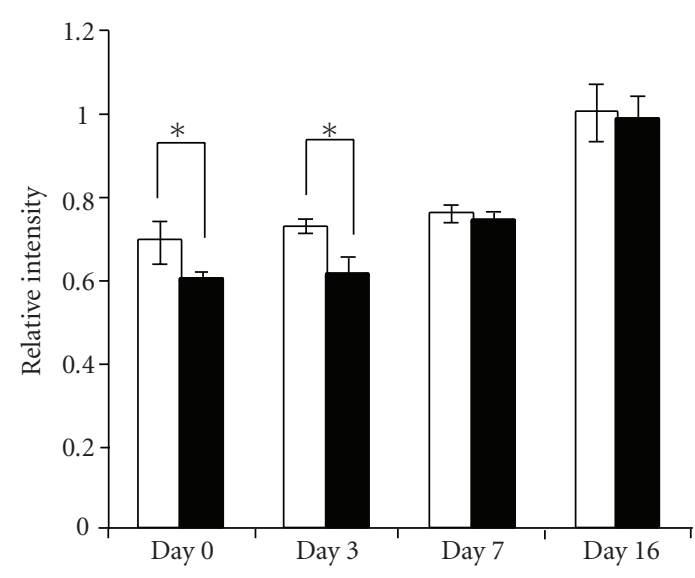

P19CL6

P19CL6-A1

(b)

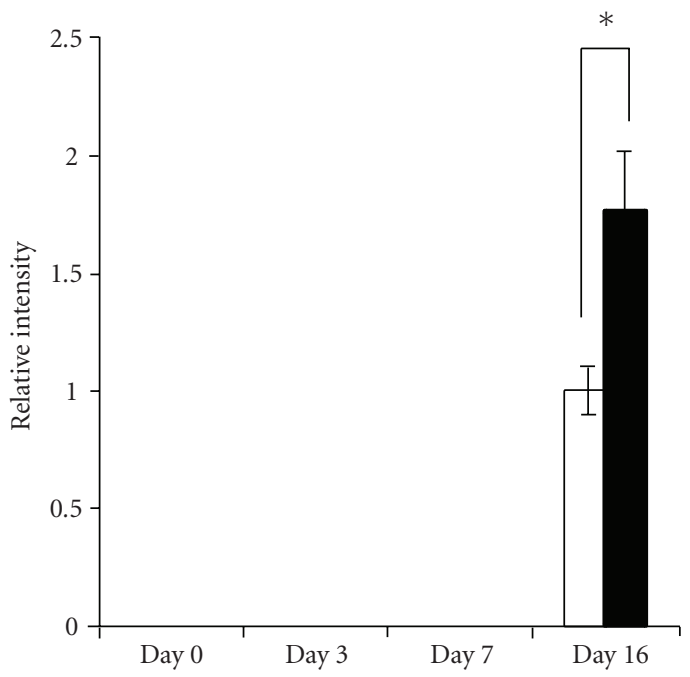

(d)

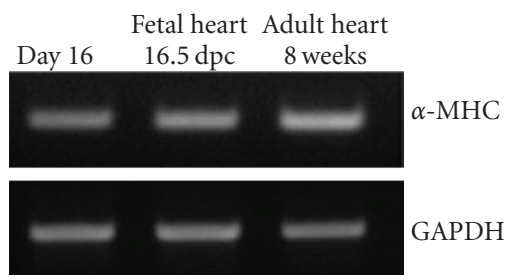

(e)

Figure 3: Amplification of GATA4, Nkx2-5, and $\alpha$-MHC mRNAs by RT-PCR. (a) Expression of GATA4, Nkx2-5, and $\alpha$-MHC in the P19CL6 cells differentiated by the basal protocol and the P19CL6-A1 cells by the developed protocol on day 0 and 16, respectively. ((b), (c) and (d)) Densitometric quantification of the amplification levels of GATA4 (b), Nkx2-5 (c), and $\alpha$-MHC (d) in the P19CL6 and P19CL6-A1 cells in the respective differentiation protocols on day $0,3,7$, and 16. Data from three independent experiments, normalized to the levels of the GAPDH amplification products, are shown as mean \pm SE. Comparisons between the data of P19CL6 and P19CL6-A1 cells were performed using unpaired $t$-test. ${ }^{*} P<.05$ (e) Amplification of $\alpha$-MHC mRNAs by RT-PCR in the P19CL6-A1 cells differentiated by the developed protocol with DMEM on day 16 , and the heart ventricles of $16.5 \mathrm{dpc}$ fetal and 8 -week-old mice. 

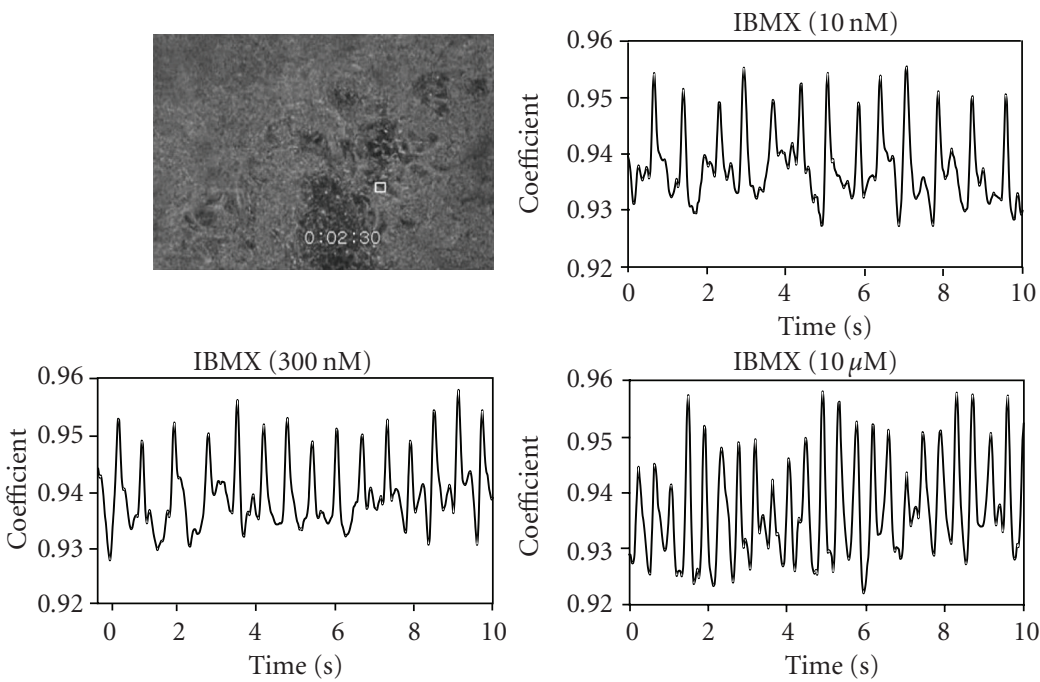

(a)
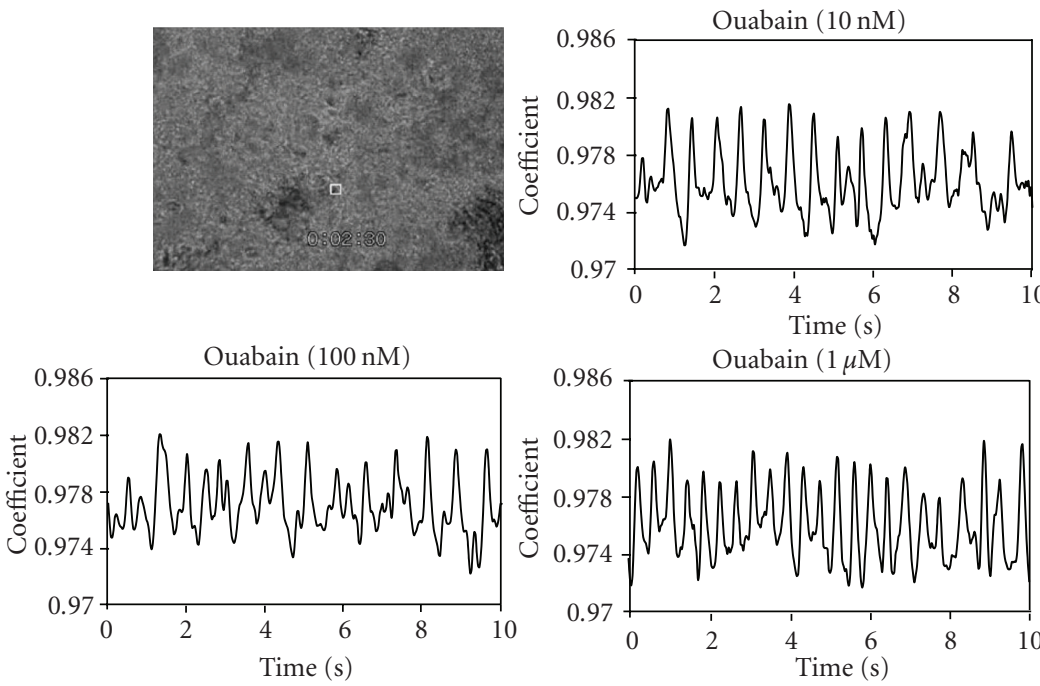

(c)

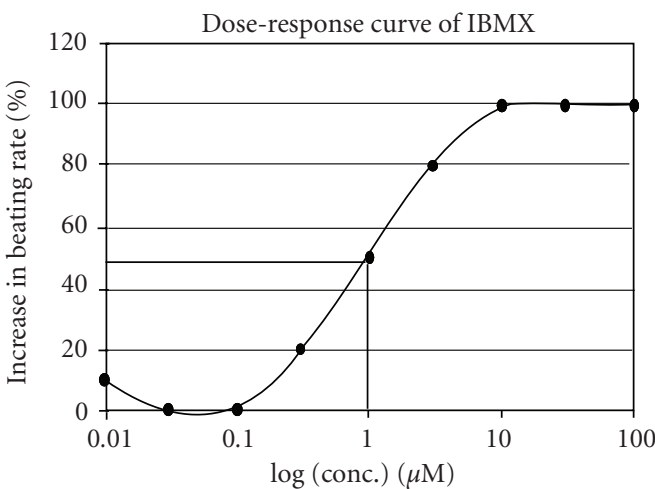

(b)

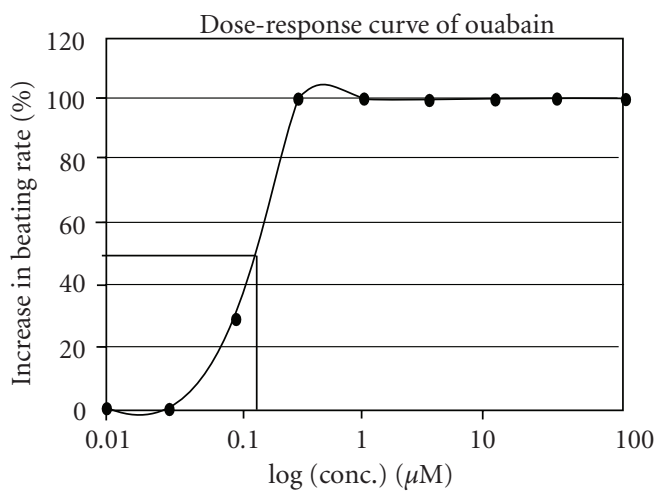

(d)

Figure 4: The pharmacological reactions of the P19CL6-A1-derived cardiomyocytes. The contraction rhythms of the beating cells are analyzed on the moving images before and after addition of the serial dilutions of IBMX (a) and ouabain (c) using the VisoRhythm software on which the temporal variations in the correlation coefficient are calculated between the values of mean brightness of the reference frame and those of other frames in the selected area $(20 \times 20$ pixels in white), and accordingly, the correlograms representing the contraction rhythm of the beating cells are displayed by the vertical coefficient and horizontal time axis. ((b) and (d)) The median effective doses (ED 50 ) of IBMX (b) and ouabain (d) obtained from the dose-response curve based on the beating rates, on which the basal and maximum rates are represented by 0 and $100 \%$, are $950 \mathrm{nM}$ and $160 \mathrm{nM}$, respectively.

investigations are necessary to elucidate whether multilayer formation is a crucial trigger for differentiation and to determine the molecular events occurring in the multilayer regions in this instance.

We employed the double stimulation method using 5Aza and DMSO as suggested by Ohtsu et al. [12], as the basal protocol for cardiomyocyte differentiation because it elicited differentiation from the parent P19CL6 cells most efficiently among the several differentiation methods as long as it was in vitro in our laboratory. To apply it to the clonal derivative, that is, to P19CL6-A1 cells, we examined the optimum concentration and exposure time of the inducers and accordingly, the protocol for efficient differentiation was modified as summarized in Table 1. The optimum concentration of each inducer is the same as that in the basal protocol, but the exposure time of 5Aza is 3-fold longer than that for the parent cells. An almost equal and fair percentage of P19CL6 and P19CL6A1 cells were necrotic after treatment with $10 \mu \mathrm{M}$ 5-Aza for 24 and 72 hours, respectively, in the monolayer culture, and therefore, the P19CL6-A1 cells were more resistant to more prolonged exposure to the DNA demethylating reagent than the P19CL6 cells. Both cell types were much more resistant to the reagent than the P19 cells because the P19 cells treated with 5-10 $\mu \mathrm{M}$ 5-Aza in the monolayer culture became totally necrotic [15]. In the present study, DMEM 
with $7.5 \%$ FBS of the composition of the differentiation medium elicited differentiation from both P19CL6-A1 and P19CL6 cells more efficiently than $\alpha$-MEM with $6.5 \%$ FBS and much more than $\alpha$-MEM with $10 \%$ FBS (data not shown), which has been generally used for the differentiation of P19 and P19CL6 cells [7, 11-15, 20-26]. After the 5Aza treatment, P19CL6-A1 cells proliferated slightly under DMEM containing 1\% DMSO and 7.5\% FBS and could form multicell layers in adhesion culture more extensively than P19CL6 cells under $\alpha$-MEM containing 1\% DMSO and 6.5\% FBS. P19CL6-A1-derived beating cells appeared mostly in the multilayer regions and formed clusters more extensively in the multilayer regions than in monolayer regions. These may indicate that more extensive multilayer formation induces the cardiomyocytes to differentiate more efficiently. However, using $10 \%$ FBS instead of $7.5 \%$ or $6.5 \%$ could not elicit more efficient differentiation of the cells probably due to stable proliferation of the undifferentiated populations in the cells even in the differentiation media containing $10 \%$ FBS. In the present study, we found that $1 \%$ DMSO is optimum for the differentiation of P19CL6 and P19CL6-A1 cells. It is generally used for differentiation of P19 and P19CL6 cells [11-15, 20, 22-26]. Moreover, a previous report has demonstrated that the efficiency of colony formation of P19 cells in the presence of DMSO indicates the absence of toxicity at concentrations of less than $1 \%$ under $\alpha$-MEM with $10 \%$ FBS [7]. Based on these data, we suppose that the serum concentration in combination with $1 \%$ DMSO is a considerable factor for efficient differentiation. In fact, the source and lot number of FBS and calf serum used in differentiation are thought to be crucial for successful cardiac differentiation from P19 cells [16] as well as from P19CL6 cells (RIKEN BioResource Center, personal communication).

In the present study, cardiac-specific transcription factors GATA4 and Nkx2-5 were expressed in untreated cells. In most previous reports P19CL6 cells untreated with inducers such as DMSO and 5-Aza expressed neither GATA4 nor Nkx2-5 [12, 14, 20, 22, 24, 27]. However, there are a few reports in which GATA4 and/or Nkx2-5 expressed in P19CL6 cells before the treatment $[23,26]$. In the present study we used a medium containing 10\% DMSO for cell cryopreservation and cells cultured for 1 day after thawing as untreated cells (day 0) for the experiments. We suppose this caused the clear expressions because the untreated cells contain cells already exposed to the DMSO as a cardiac differentiation inducer probably at a high rate. There were no differences in the differentiation efficiencies under an inverted microscope between P19CL6-A1 cells with and without subcultures after thawing (data not shown) and the same finding was obtained on P19CL6 cells (Dr. Y Ohtsu, Jichi Medical University, personal communication).

There are 2 isoforms of cardiac MHCs, namely $\alpha$ - and B-MHC. The former is characterized by a high ATPase activity and a quick contraction velocity as compared to the latter [28]. Alpha- and/or B-MHC are often used as cardiacspecific markers for determining the efficiencies of cardiac differentiation of P19 and P19CL6 cells $[8,11,13,14,20$, $25]$. In the present study, we showed that the expression level of $\alpha$-MHC mRNA in the P19CL6-A1 cells treated with the inducers was significantly and 1.77 times higher than that in the P19CL6 cells and almost equal to that in the heart ventricles of the mouse fetuses. This indicates a high efficiency of cardiac differentiation of P19CL6-A1 cells. We also compared the differentiation efficiency between the two cells by using cardiac $\alpha$-actin immunofluorescence staining and showed that the ratio of cardiac $\alpha$-actin-positive cell areas to total areas of microscopic fields in P19CL6-A1 cells was $38.3 \%$ and 5.5 times higher than that in P19CL6 cells. This indicates that the differentiation efficiency estimated by the immunofluorescence staining is 3.1 times higher than that by the RT-PCR. This discrepancy is likely to be caused by the multicell layer formation of P19CL6-A1 cells; the twodimensionally microscopic analysis may overestimate the differentiation efficiency due to the elimination of a factor in rate of formation of multicell layers and the estimation by the RT-PCR may represent the differentiation efficiency close to a real value.

4.2. Cardiomyocytes from P19CL6-A1 Cells. P19- as well as P19CL6-derived cardiomyocytes display an electrophysiological phenotype of embryonic ventricular cardiomyocytes based on the studies in which (1) they display a complete set of functional ion channels, but only limited amount of functional sodium channels, (2) the maximal diastolic potential is rather low (approximately -40 to $-60 \mathrm{mV}$ ), and (3) the shape and characteristics of the action potential of these cells resemble those of primary isolated embryonic cardiomyocytes [5, 21, 24, 29]. Thus, P19CL6-A1-derived cardiomyocytes may have similar properties because they are clonal derivatives of P19CL6 cells. They rhythmically and spontaneously beat and form clusters much larger than P19CL6-derived cardiomyocytes, and accordingly their contractions are larger and more obvious as observed under an inverted microscope. Therefore, P19CL6-A1-derived cardiomyocytes may be suitable models for studies on the cardiac structural and functional properties during normal physiological and pathological states in vitro, particularly studies on contraction rhythm analyses based on moving images. For this purpose, that is, to figure out the temporal variations in the beating rhythms in detail, we developed the software, Visorhythm, to analyze them based on moving images and chart correlograms displaying the oscillated rhythms. To illustrate the availability of P19CL6-A1-derived cardiomyocytes as physiologically functional cardiomyocytes and the software as an analytical tool for detailed analysis of beating rhythms, we employed IBMX and ouabain as potent cardiotonic reagents $[30,31]$. Additionally, we found that the nonbeating cells started to contract rhythmically after the addition of these reagents (data not shown). This finding is supported by a previous study in which P19derived nonbeating cells generated action potentials upon electrical stimulation [5] and indicates that the actual ratio of P19CL6-A1-derived cardiomyocytes is higher than that of the beating to nonbeating cells under the microscope.

There are largely two different methods to analyze beating rhythms of cardiomyocytes in vitro: one is an 
electrophysiological method to measure electrical potential of cardiomyocytes and the other is a microscopic method to measure oscillated motions of cardiomyocytes. As for the former method, a culture plate equipped with microelectrode arrays having 64-channels are used to record electrical potentials on cultured cardiomyocytes [32, 33]. It can analyze electrical activities of cardiomyocytes such as conduction velocities and synchronization times. As for microscopic methods, Micheletto et al. introduced a freerunning scanning near-field optical microscopy setup to observe live cardiomyocytes [34]. Weisensee et al. also introduced an image analysis system using the video capture board for real-time subtraction between frames of moving images to analyze motions of beating cardiomyocytes [35]. Both tools can analyze beating rates and the relative strength for inotropic force while they monitor only one object at a time. Here we have introduced Visorhythm to analyze temporal variations in beating rhythms of cardiomyocytes based on moving images and chart correlograms displaying the oscillated rhythms. This software can analyze beating rates easily. Yamauchi et al. had developed a similar software on which the temporal variations in beating rhythms could be analyzed in 1 fixed area $(20 \times 20$ pixels $)$ chosen arbitrarily [18]. In contrast, Visorhythm can analyze up to 6 such areas (150-400 pixels/area) on each frame of one moving image simultaneously. Therefore it can also analyze synchronization between cardiomyocytes.

In conclusion, we used double stimulation with 5-Aza and DMSO in this study and showed that P19CL6-A1 cells, a new clonal derivative of P19CL6 cells, differentiated into cardiomyocytes more efficiently than the parent cells. We introduced a new software, Visorhythm, that can analyze the temporal variations in the beating rhythms and can chart correlograms displaying the oscillated rhythms up to 6 areas on a single moving image simultaneously. Using P19CL6-A1derived cardiomyocytes and the software, we demonstrated that the correlograms could clearly display the enhancement of beating rates by cardiotonic reagents. These indicate that a combination of P19CL6-A1 cells and Visorhythm is a useful tool that can provide invaluable assistance in inotropic drug discovery, drug screening, and toxicity testing.

\section{Acknowledgments}

The authors would like to thank Dr. Yoshiko Yamauchi and Professor Koichi Kawahara for kindly providing the data analysis algorithm on the calculation of the correlation coefficient based on moving images, Mr. Stefan Mueller for help with VisoRhythm software programming, and Dr. Yoshinori Ohtsu for kindly providing the P19CL6 differentiation protocol. This work was supported by a Grant-in-Aid for Scientific Research from Japan Society for the Promotion of Science (to K. O.; no. 18580296).

\section{References}

[1] S. Itescu, M. D. Schuster, and A. A. Kocher, "New directions in strategies using cell therapy for heart disease," Journal of Molecular Medicine, vol. 81, no. 5, pp. 288-296, 2003.
[2] I. Kehat and L. Gepstein, "Human embryonic stem cells for myocardial regeneration," Heart Failure Reviews, vol. 8, no. 3, pp. 229-236, 2003.

[3] L. Gepstein, "Derivation and potential applications of human embryonic stem cells," Circulation Research, vol. 91, no. 10, pp. 866-876, 2002.

[4] S. Lev, I. Kehat, and L. Gepstein, "Differentiation pathways in human embryonic stem cell-derived cardiomyocytes," Annals of the New York Academy of Sciences, vol. 1047, pp. 50-65, 2005.

[5] M. A. G. van der Heyden and L. H. K. Defize, "Twenty one years of P19 cells: what an embryonal carcinoma cell line taught us about cardiomyocyte differentiation," Cardiovascular Research, vol. 58, no. 2, pp. 292-302, 2003.

[6] H. Wei, O. Juhasz, J. Li, Y. S. Tarasova, and K. R. Boheler, "Embryonic stem cells and cardiomyocyte differentiation: phenotypic and molecular analyses," Journal of Cellular and Molecular Medicine, vol. 9, no. 4, pp. 804-817, 2005.

[7] M. W. McBurney, E. M. V. Jones-Villeneuve, M. K. S. Edwards, and P. J. Anderson, "Control of muscle and neuronal differentiation in a cultured embryonal carcinoma cell line," Nature, vol. 299, no. 5879, pp. 165-167, 1982.

[8] I. S. Skerjanc, "Cardiac and skeletal muscle development in P19 embryonal carcinoma cells," Trends in Cardiovascular Medicine, vol. 9, no. 5, pp. 139-143, 1999.

[9] M. W. McBurney, "P19 embryonal carcinoma cells," International Journal of Developmental Biology, vol. 37, no. 1, pp. 135140, 1993.

[10] J. Paquin, B. A. Danalache, M. Jankowski, S. M. McCann, and J. Gutkowska, "Oxytocin induces differentiation of P19 embryonic stem cells to cardiomyocytes," Proceedings of the National Academy of Sciences of the United States of America, vol. 99, no. 14, pp. 9550-9555, 2002.

[11] A. Habara-Ohkubo, "Differentiation of beating cardiac muscle cells from a derivative of P19 embryonal carcinoma cells," Cell Structure and Function, vol. 21, no. 2, pp. 101-110, 1996.

[12] Y. Ohtsu, K. Johkura, K.-I. Ito, et al., "Stimulation of P19CL6 with multiple reagents induces pulsating particles in vivo," Current Medical Research and Opinion, vol. 21, no. 5, pp. 795803, 2005.

[13] F. Fathi, S. Murasawa, S. Hasegawa, T. Asahara, A. J. Kermani, and S. J. Mowla, "Cardiac differentiation of P19CL6 cells by oxytocin," International Journal of Cardiology, vol. 134, no. 1, pp. 75-81, 2009.

[14] D. Kami, I. Shiojima, H. Makino, et al., "Gremlin enhances the determined path to cardiomyogenesis," PLOS ONE, vol. 3, no. 6, article e2407, 2008.

[15] S.-C. Choi, J. Yoon, W.-J. Shim, Y.-M. Ro, and D.-S. Lim, "5azacytidine induces cardiac differentiation of P19 embryonic stem cells," Experimental and Molecular Medicine, vol. 36, no. 6, pp. 515-523, 2004.

[16] S. Wilton and I. Skerjanc, "Factors in serum regulate muscle development in P19 cells," In Vitro Cellular and Developmental Biology-Animal, vol. 35, no. 4, pp. 175-177, 1999.

[17] B. G. Bruneau, "Transcriptional regulation of vertebrate cardiac morphogenesis," Circulation Research, vol. 90, no. 5, pp. 509-519, 2002.

[18] Y. Yamauchi, A. Harada, and K. Kawahara, "Changes in the fluctuation of interbeat intervals in spontaneously beating cultured cardiac myocytes: experimental and modeling studies," Biological Cybernetics, vol. 86, no. 2, pp. 147-154, 2002.

[19] P. J. Gianakopoulos and I. S. Skerjanc, "Hedgehog signaling induces cardiomyogenesis in P19 cells," Journal of Biological Chemistry, vol. 280, no. 22, pp. 21022-21028, 2005. 
[20] J.-Y. Lim, W. H. Kim, J. Kim, and S. I. Park, "Involvement of TGF- $\beta 1$ signaling in cardiomyocyte differentiation from P19CL6 cells," Molecules and Cells, vol. 24, no. 3, pp. 431-436, 2007.

[21] J. C. Moore, R. Spijker, A. C. Martens, et al., "A P19CI6 GFP reporter line to quantify cardiomyocyte differentiation of stem cells," International Journal of Developmental Biology, vol. 48, no. 1, pp. 47-55, 2004

[22] T. Nakane, T. Satoh, Y. Inada, J. Nakayama, F. Itoh, and S. Chiba, "Molecular cloning and expression of HRLRRP, a novel heart-restricted leucine-rich repeat protein," Biochemical and Biophysical Research Communications, vol. 314, no. 4, pp. 1086-1092, 2004.

[23] Y. Ohara, T. Atarashi, T. Ishibashi, A. Ohashi-Kobayashi, and M. Maeda, "GATA-4 gene organization and analysis of its promoter," Biological and Pharmaceutical Bulletin, vol. 29, no. 3, pp. 410-419, 2006.

[24] C.-F. Peng, Y. Wei, J. M. Levsky, T. V. McDonald, G. Childs, and R. N. Kitsis, "Microarray analysis of global changes in gene expression during cardiac myocyte differentiation," Physiological Genomics, vol. 9, no. 3, pp. 145-155, 2002.

[25] S. Uchida, S. Fuke, and T. Tsukahara, "Upregulations of Gata4 and oxytocin receptor are important in cardiomyocyte differentiation processes of P19CL6 cells," Journal of Cellular Biochemistry, vol. 100, no. 3, pp. 629-641, 2007.

[26] J. Wen, Q. Xia, C. Lu, et al., "Proteomic analysis of cardiomyocytes differentiation in mouse embryonic carcinoma P19CL6 cells," Journal of Cellular Biochemistry, vol. 102, no. 1, pp. 149160, 2007.

[27] A. Alexandrovich, M. Arno, R. K. Patient, A. M. Shah, J. A. Pizzey, and A. C. Brewer, "Wnt2 is a direct downstream target of GATA6 during early cardiogenesis," Mechanisms of Development, vol. 123, no. 4, pp. 297-311, 2006.

[28] E. M. McNally, R. Kraft, M. Bravo-Zehnder, D. A. Taylor, and L. A. Leinwand, "Full-length rat alpha and beta cardiac myosin heavy chain sequences. Comparisons suggest a molecular basis for functional differences," Journal of Molecular Biology, vol. 210, no. 3, pp. 665-671, 1989.

[29] A. M. Wobus, T. Kleppisch, V. Maltsev, and J. Hescheler, "Cardiomyocyte-like cells differentiated in vitro from embryonic carcinoma cells P19 are characterized by functional expression of adrenoceptors and $\mathrm{Ca} 2^{+}$channels," In Vitro Cellular and Developmental Biology-Animal, vol. 30 A, no. 7, pp. 425-434, 1994.

[30] H. Brasch and H. Iven, "Inotropic and electrophysiological effects of BDF 9148, a congener of DPI 201-106, in guinea-pig atria and papillary muscles," British Journal of Pharmacology, vol. 103, no. 4, pp. 1939-1945, 1991.

[31] D. G. Wynne, P. A. Poole-Wilson, and S. E. Harding, "Incomplete reversal of $\beta$-adrenoceptor desensitization in human and guinea-pig cardiomyocytes by cyclic nucleotide phosphodiesterase inhibitors," British Journal of Pharmacology, vol. 109, no. 4, pp. 1071-1078, 1993.

[32] Y. Haraguchi, T. Shimizu, M. Yamato, A. Kikuchi, and T. Okano, "Electrical coupling of cardiomyocyte sheets occurs rapidly via functional gap junction formation," Biomaterials, vol. 27, no. 27, pp. 4765-4774, 2006.

[33] C.-K. Yeung, F. Sommerhage, G. Wrobel, et al., "To establish a pharmacological experimental platform for the study of cardiac hypoxia using the microelectrode array," Journal of Pharmacological and Toxicological Methods, vol. 59, no. 3, pp. 146-152, 2009.

[34] R. Micheletto, M. Denyer, M. Scholl, et al., "Observation of the dynamics of live cardiomyocytes through a free-running scanning near-field optical microscopy setup," Applied Optics, vol. 38, no. 31, pp. 6648-6652, 1999.

[35] D. Weisensee, T. Seeger, A. Bittner, J. Bereither-Hahn, W. Schoeppe, and I. Low-Friedrich, "Cocultures of fetal and adult cardiomyocytes yield rhythmically beating rod shaped heart cells from adult rats," In Vitro Cellular and Developmental Biology-Animal, vol. 31, no. 3, pp. 190-195, 1995. 

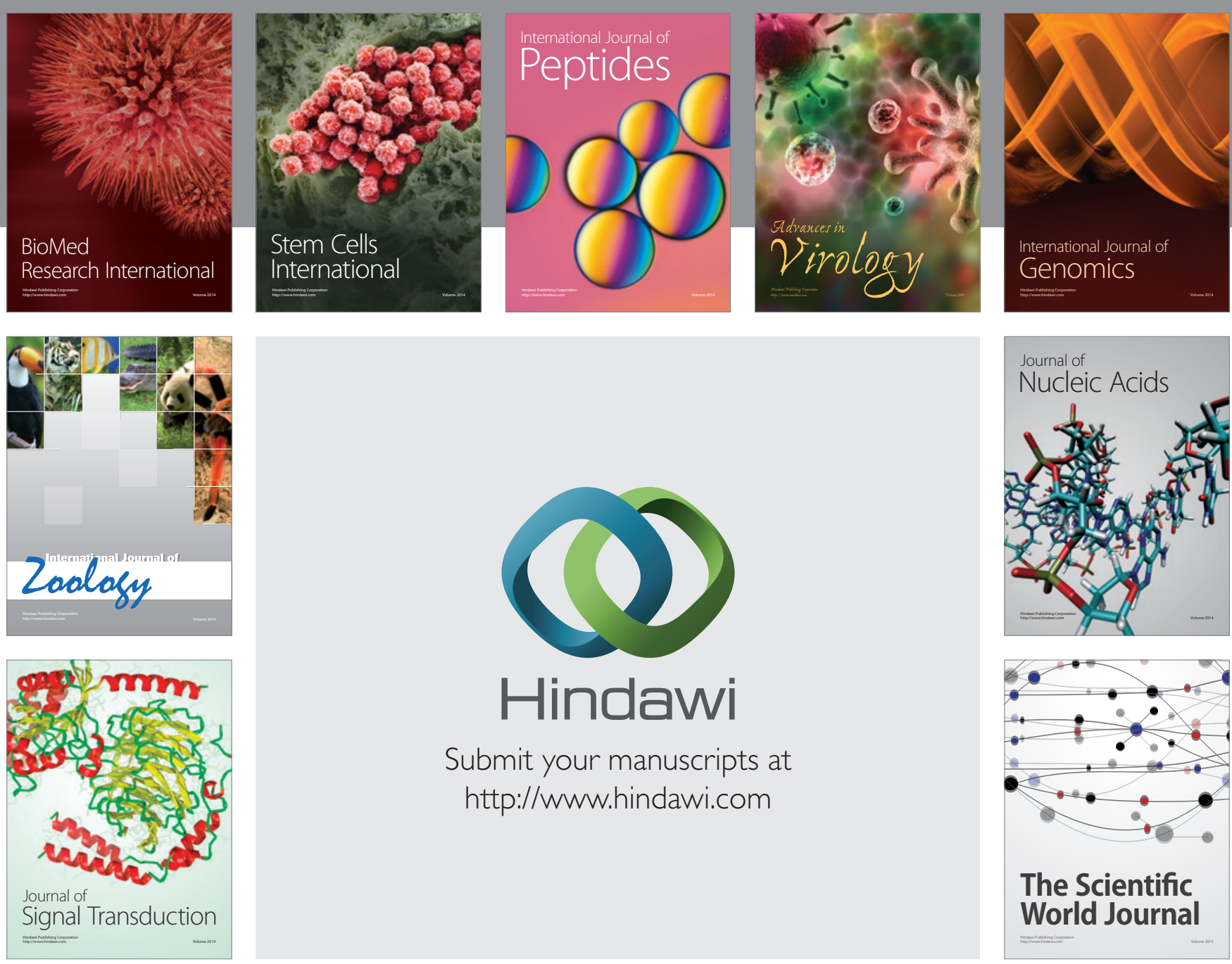

Submit your manuscripts at

http://www.hindawi.com
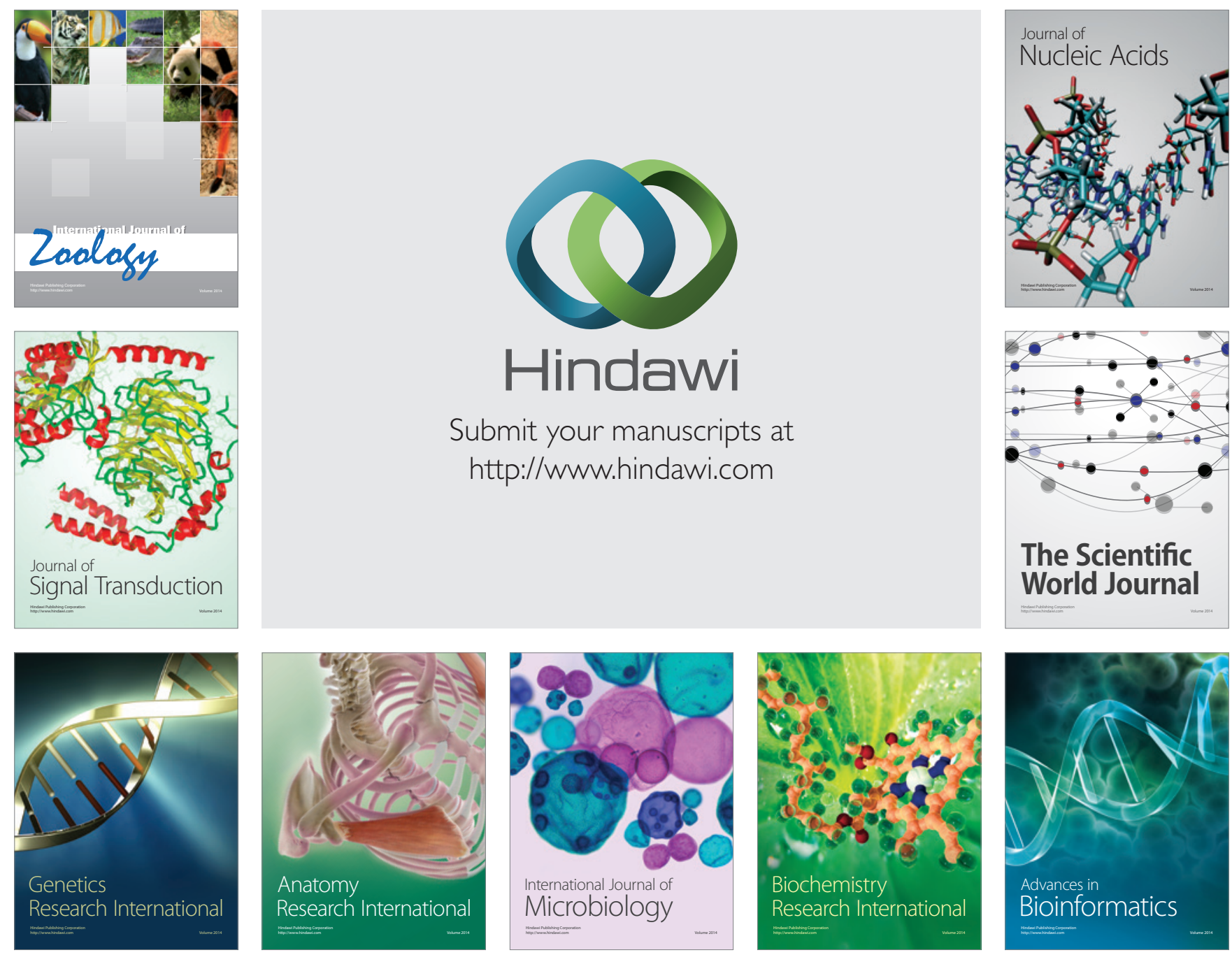

The Scientific World Journal
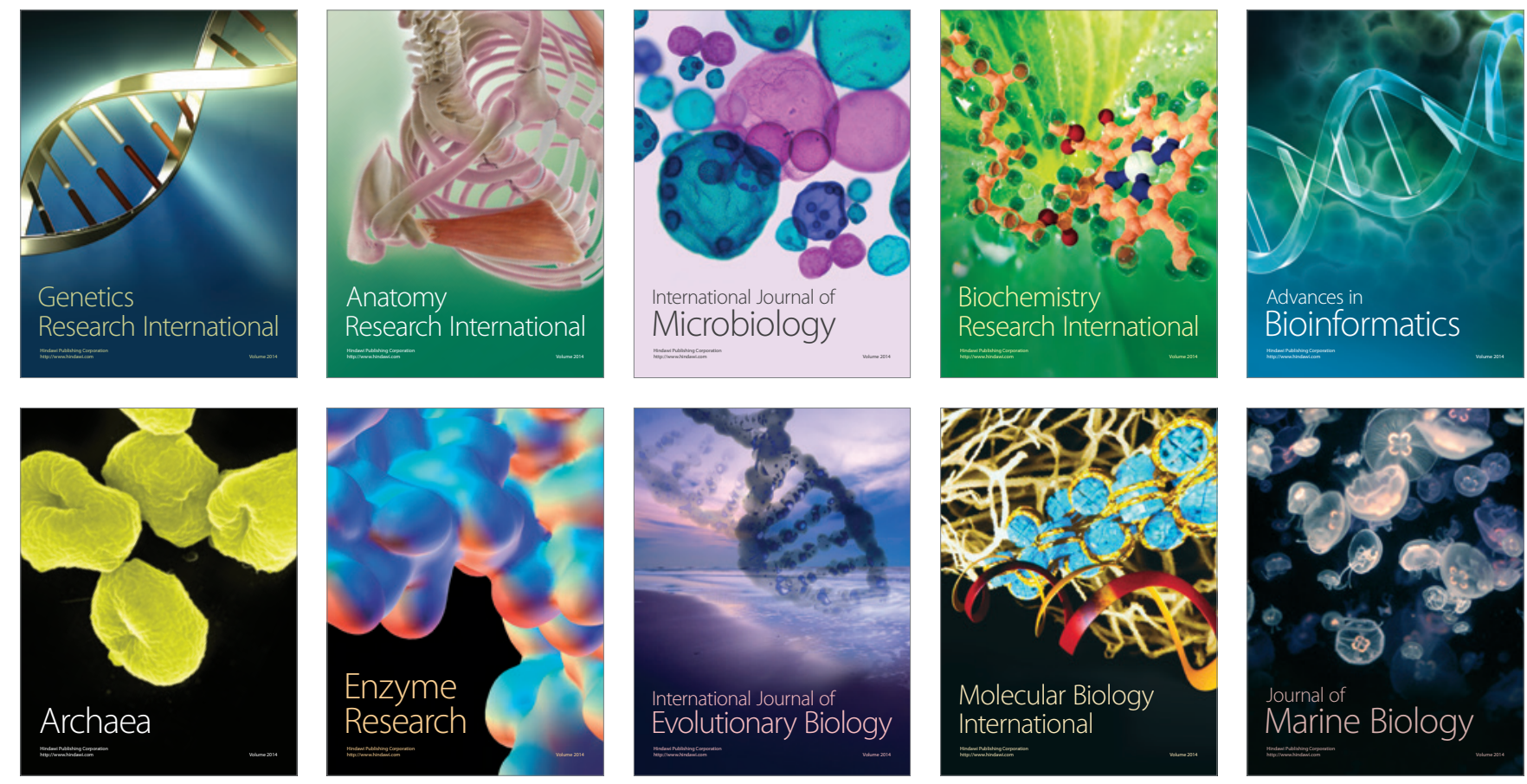